\title{
Casa aristocrática de lavradores: o topos do de re rustica nas epístolas em verso de Sá de Miranda
}

\author{
Ricardo Hiroyuki Shibata[1]
}

\begin{abstract}
Resumo
Este artigo procura investigar algumas coordenadas epocais presentes nas epístolas em verso de Francisco de Sá de Miranda (1481-1558).É possível afirmar que a argumentação principal de Sá de Miranda reside na defesa de um “tempo da memória”, que deve ser preservado, em oposição estratégica às vicissitudes da expansão marítima portuguesa e do tempo presente. Isso se faz a partir da mobilização da doutrina da "economia" (oeconomia), da "casa" (oikos) e de matéria correlata, cuja vitalidade foi reativada pelo Renascimento, com tradução literária nos lugares-comuns do de re rustica (assunto de agricultura e de camponeses). Dos tempos clássicos até a Idade Moderna, todo esse conjunto normativo não tratava somente das questões de administração da família e da conservação do patrimônio, mas também da agricultura e das relações de amizade.

Palavras-chave: Renascimento; navegações portuguesas; Idade Moderna.
\end{abstract}

La casa aristocrática de labradores: el topos del de re rustica en las epístolas en verso de Sá de Miranda

\section{Resumen}

Este artículo busca investigar algunas coordenadas de época presentes en las epístolas en verso de Francisco de Sá de Miranda (1481-1558). Es posible argüir que el principal argumento de Sá de Miranda es la defensa de un "tiempo de la memoria", que debe preservarse, en oposición estratégica a las vicisitudes de la expansión marítima portuguesa y del momento actual. Esto se hace desde la movilización de la doctrina de la "economía" (oeconomia), la "casa" (oikos) y asuntos conexos, cuya vitalidad fue reactivada por el Renacimiento, con traducción literaria en los lugares comunes del de re rustica (tema de la agricultura y los campesinos). Desde la Época Clásica hasta la Edad Moderna, todo este conjunto de normas no sólo abordaba los problemas de gestión de la familia y la conservación del patrimonio, sino también de la agricultura y las relaciones de amistad.

Palabras clave: Renacimiento; navegaciones portuguesas; Edad Moderna.

Aristocratic house of farmers: the topos of the de re rustica in Sá de Miranda's verse epistles

\section{Abstract}

This paper analyses the Francisco de Sá de Miranda's verse epistles according to some historical boundaries. It is clear that Sá de Miranda's main reason lied on the defense of "time of memory", which must be preserved, against the Portuguese expansion and the present time. To do so, Sá de Miranda proposed some doctrinal aspects of "economics" (oeconomia), "house" (oikos) and related subjects, whose vitality was reactivated in the Renaissance, through the literary translation of the so called de re rustica (subject of farmers and peasants). From classical times to the Modern Age, the "house" (oikos) was not only a question of family administration and conservation of the real state, but also of agriculture and friendship bonds. Keywords: Renaissance; Portuguese expansion; Modern Age.

\section{Maison aristocratique des agriculteurs: les topos de re rustica dans les épîtres de Sá de Miranda}

\section{Résumé}

Cet article examine certaines coordonnées d'époque présents dans les épîtres en vers de Sá de Miranda (1481-1558). On peut faire valoir que le principal argument de Sá de Miranda est la défense d'un «temps de la mémoire», qui doit être préservé dans l'opposition stratégique pour les vicissitudes de l'expansion maritime portugaise et du temps présent. Cela se fait à partir de la mobilisation de la doctrine de «léconomie» (oeconomia), la «maison» (oikos) et des questions connexes, dont la vitalité a été réactivée par la Renaissance, avec la traduction littéraire dans les lieux communs de re rustica (une affaire de l'agriculture et les agriculteurs). De l'Antiquité à l'époque moderne, cet ensemble de règles n'était pas seulement les questions de gestion de la famille et de la conservation du patrimoine, mais aussi de lagriculture et des relations amicales. Mots clés: Renaissance; navigations portugaises; Âge Moderne. 
Dichoso el que vive y muere En su casa! Que en su casa hasta los pobres son reyes.

Lope de Vega, El Duque de Viseo.

$\mathrm{N}$ o interior das práticas literárias de cariz ético-político da Idade Moderna, o tema da "casa" (oikos) e seus correlatos (família, relações consanguinidade, laços matrimoniais, por exemplo) é absolutamente recorrente e estratégico, conquanto tenha despertado pouco interesse para a historiografia até o momento. Em particular, a partir de certo contexto ibérico quinhentista, penso que é possível reconhecer que esse conjunto de lugares-comuns é aplicado como lugares retóricos da inventio de muita correspondência do período das navegações - muita dela, de caráter admoestatório.

É justamente, nesse sentido, que as epístolas em verso de Francisco de Sá de Miranda (1481-1558) são particularmente contundentes quando criticam a expansão portuguesa no ultramar e o comércio como formas de angariar dinheiro e acumular riquezas. Para além de seus efeitos morais negativos, Sá de Miranda entende que é absolutamente indigno ao varão de estirpe nobre envolver-se com os "tratos de mercadoria" ${ }^{1}$, mesmo porque há outras formas mais condizentes com a tradição antiga e com os valores mais prestigiosos da aristocracia de sangue.

Em vários discursos do Antigo Regime, em Portugal, é notável a referência a um "tempo da memória" que deve ser preservado, pois é ele que unifica e estabiliza os diversos laços sociais que se estabelecem no interior da comunidade política. E é justamente em nome desse tempo passado que Sá de Miranda evoca os topoi clássicos da oeconomia, em especial, como o entendia o pensamento de Xenofonte e outros teorizadores de matéria correlata.

Como se sabe, os livros do Oeconomicus, de Xenofonte, cuja influência foi surpreendente durante o Humanismo, são divididos em duas partes: a primeira, em que o jovem rico Critobolo pergunta a Sócrates qual a melhor maneira de administrar seu patrimônio, e a segunda, em que Sócrates narra a Critobolo a conversa que teve com o nobre abastado Iscômaco. De ambos, Critobolo poderá identificar os elementos essenciais que constituem a "téchne oeconomica" e todas as suas vantagens para a família, para si mesmo e para a política. A economia de que se fala não é a economia política desenvolvida a partir do século XVIII e ligada ao nascimento do conceito de Estado burguês com a descrição analítica das regras de mercado.

Em verdade, a arte da economia antiga é um saber típico do "pai de família" e constitui, em suas grandes linhas interpretativas, uma verdadeira doutrina da "casa como complexo", cujo escopo delimita as formas não só de angariar e acumular dinheiro, mas, sobretudo, da boa administração da família, dos costumes do marido como chefe da casa, da mulher, dos filhos, dos servos, dos amigos e da gestão do patrimônio familiar, composto por bens móveis e imóveis. Aristóteles, na Política (I, 3, 1253b 3-14), referia que todos os aspectos centrais da economia

'Francisco de Sá de Miranda, Poesias de Francisco de Sá de Miranda, v. 238, Lisboa, INCM, 1989, p. 243 
derivavam das partes que constituem a casa. Em particular, salientava o fato de que três tipos de relação social mantinham e estabilizavam a casa e a família para empreender seus fins: senhor-escravo, marido-esposa e pai-filho. Assim, a economia, em resumo, para Aristóteles, derivava das três funções possíveis a serem exercidas pelo aristocrata e nobre homem: a arte do senhor, do marido e do pai. ${ }^{2}$

A economia, entendida como doutrina do oikos, era, então, a área de exercício de uma forma de domínio específico - aquele do despostes ou pater familias, personagem que em nada lembra a figura sentimental e romântica do homem que vive para cuidar de sua prole e esposa. Para o pensamento antigo, o poder paternal configurava-se, antes de tudo, numa esfera de poder específico (a contraposição se fazia com o âmbito da política), com limites e obrigações muito determinadas, que se realizava por meio de uma arte nobiliar, cujo análogo era a capacidade do homem de dominar a si mesmo, no campo ético, e do cidadão de intervir nas questões relativas ao governo da cidade, no campo político. ${ }^{3}$ A força dessa tradição pode ser flagrada nas palavras do De Senectute (XVII, 59), de Cícero, autor de importantes tratados para o pensamento humanista, em que Catão refere-se a Xenofonte como a origem de todo o pensamento econômico: in eo libro qui est tuenda rei familiari ("aquele que resumiu a doutrina da casa e da família").

É, justamente, com base nessa doutrina que Sá de Miranda prescreve quais são as atividades dignas do nobre e virtuoso senhor da casa e pai de família, não só naquilo que concerne ao seu dever de levantar os bens necessários para prover seus familiares, mas também na arte de dispender dinheiro, como expressão da virtude da justiça distributiva, liberalidade e magnificência. Nesse sentido, para Sá de Miranda, seguindo o topos horaciano do fugere urbem ("fugir da cidade"), o retiro da corte para o ambiente campestre significa a "liberdade" de governar o que verdadeiramente lhe pertence por direito (e não a busca de honras e privilégios conseguidos pelo serviço a outro senhor; para ele, isso era apenas "servidão"). Em sentido complementar, Sá de Miranda sinalizava que o único meio digno de obter riquezas e manter-se financeiramente independente era dedicar-se à agricultura.

Isso é particularmente claro, quando, na carta "A Antonio Pereira", Sá de Miranda lembrava o convívio que os dois verdadeiros amigos travavam na quinta do senhor de Basto em meio a banquetes frugais e em companhia das letras. As tópicas desse bom convívio são dadas pela glosa ao O fortunatos nimium, sua si bona norint / agricolae ("por demais felizes seriam os camponeses, se soubessem das riquezas que possuem") das Geórgicas (II. 457-458) de Virgílio. Ou, para frisar de outro modo, conforme a mesma matriz econômica antiga, com o El catón en latin y en romance, de Gonzalo García de Sancta María, todos aqueles que desejarem desvendar o real significado das práticas de agricultura deviam ler as páginas de Virgílio:

\footnotetext{
${ }^{2}$ Ver, por exemplo, Rafaello Volaterrano, Commentariorum urbanorum... Oeconomicus Xenophontis, In: Scriptores rei rusticae, Veneza, Aldo Manúcio, 1514 (Seção de Obras Raras/Biblioteca Nacional do Rio de Janeiro, n. 213, 2, 14).

${ }^{3}$ Christopher Dyer, "Alternative approaches to the history of agriculture", Past \& Present, vol. 68, 2000, p. 254 -262.
} 
Si la arte quisieres de la agricultura

Saber: leeras aquel gran Mantuano:

Poeta Virgilio: ahun q[ue] pagano.

Mas si quisieres quiçá la natura

Saber de las hyerbas: difficil: [e] escura

Hacer auctor excellente: [e] approbado

Te lo díra por su verso: [e] dictado

Muy claro. sin glosa: [e] sin outra figura. ${ }^{4}$

$\mathrm{Ou}$, ainda, para referir a enorme vitalidade desse topos, basta afirmar com Sá de Miranda, a partir da glosa de um dito sentencioso retirado do "Prefácio" do De agricultura, de Catão ("et virum bonum quon laudabant, ita laudabant: bonum agricolam bonumque colonum", "os homens virtuosos de antigamente somente apreciavam a virtude do bom agricultor e do bom fazendeiro"): ${ }^{5}$
Nossos maiores se alguem
Louvavão, não de senhor,
Não de rico era o louvor,
Chamavão lhe homem de bem,
E ainda bom lavrador.
A nossa gente nos louvores
Que agora parecem vis,
Aos bons reis Sancho e Denis
Chamavão lhe lavradores. ${ }^{6}$

De acordo com os principais autores romanos de tratados de agricultura, Catão era famoso por seu arraigado tradicionalismo. Para Columela, era mesmo considerado um autor "campônio", vale dizer, ultrapassado em comparação com outros autores mais modernos que se preocupavam com métodos mais racionais de exploração da terra e organização dos processos de trabalho. Alguns, inclusive, consideravam os conselhos agrícolas de Saserna mais relevantes do que os de Catão, seu pai, e chamaram a atenção para a importância do estudo da economia rural ("agricolatinoem diligentius erudierunt", "estudar diligentemente os assuntos de agricultura").

No entanto, Catão, de fato, estava muito pouco interessado nos aspectos técnicos de tirar maior rendimento das terras e do cultivo dos campos. O que lhe interessava era a agricultura como "arte" e única fonte digna de rendimentos e sustento para o homem de nascimento nobre e para a sua família. Catão, comparando a agricultura com outros meios de obter riquezas - o comércio e o empréstimo de dinheiro a juros, ou seja, as duas outras fontes mais prestigiosas de riqueza à época romana -, afirmava que não havia método mais rápido, fácil, seguro e honesto para enriquecer. Plínio, o Jovem, por sua vez, numa de

\footnotetext{
4"Se a arte da agricultura quiseres / saber: leia o grande Mantuano, / o poeta Virgílio: mesmo ele sendo pagão. / E se quiseres quem sabe conhecer / a difícil e complicada natureza das plantas, / não encontrará autor mais excelente e aprovado / Eu diria que seus versos e sentenças / são soberbos, sem necessidade de glosa ou outra explicação". Gonzalo G. Sancta María, El catón en latin y en romance, Zaragoza, Pablo Hurus, 1494, fl. ciijv (Edição fac-similar por Librerias Paris-Valencia, 1964).

5 Maria Helena Rocha Pereira, “Uma descrição poética da Lisboa quinhentista”, Humanitas, n. 35-36, 1983-1984, p. 350. ${ }^{6}$ Francisco de Sá de Miranda, Poesias de Francisco de Sá de Miranda, v. 241-250, Lisboa, INCM, 1989, p. 246.
} 
suas epístolas (II. 44), lamentava que, após anos de dedicação e esforço árduo, infelizmente, a agricultura não lhe proporcionara tantos dividendos assim, porém, a despeito do fracasso material, havia conseguido pelo menos tempo suficiente para aperfeiçoar as virtudes. ${ }^{7}$

Como diz von Albrecht, o De agricultura de Catão é um texto heterogêneo em que, a uma primeira parte bem estruturada acerca de temas de agricultura propriamente dita, alia-se uma segunda parte, onde se dão conselhos práticos de natureza heteróclita: receitas de cozinha e prescrições médicas para certas enfermidades, orações votivas e referências a costumes e hábitos antigos. Os historiadores da literatura romana afirmam que se pode tratar de uma compilação tardia ou um caderno doméstico de Catão, escrito para seu uso próprio e que depois fora acrescido de anotações. De qualquer forma, tratar-se-ia, portanto, de um manual não apenas de agricultura, mas também de normas para a manutenção e administração da vida econômica, em que o valor moral das práticas agrícolas e de todo seu arsenal de temas (criação de gado, cuidado com os servos e com a família, preservação da tradição etc.) compreenderiam inclusive a preparação para a vida militar. ${ }^{8}$

\section{Para o pensamento antigo, o poder \\ paternal configurava-se, antes de tudo, numa esfera de poder específico}

Parece claro, para todos os tratadistas romanos, que eles e Catão compartilhavam do mesmo interesse de escrever acerca da manutenção da nobre família romana em época de paz, uma vez que, em tempos de guerra, os rendimentos vinham do saque (incluindo as várias formas de corso), do pagamento de resgates, da conquista de novos territórios e da obtenção de escravos. A organização da oeconomia doméstica ganhava relevo por ser considerada, tanto numa quanto noutra época, a base na qual se assentavam todos os pilares fundamentais da sociedade e da estrutura política.

$\mathrm{O}$ aumento na riqueza da família e, por conseguinte, o sucesso na administração da casa eram os índices seguros para estabelecer qualquer ambição numa carreira nos negócios do Estado. Para Catão, vivendo num tempo em que o poderio romano se expandia vertiginosamente por tantos territórios conquistados e em que o número de "novos ricos" e sua influência política aumentavam sobremaneira - à semelhança do contexto político por que passará Portugal no século XVI —, essa riqueza e esse sucesso só poderiam vir de uma fonte tão tradicional como a agricultura em detrimento de qualquer outra forma. Sá de Miranda também compartilhava desse pensamento:

7René Martin, Recherches sur les agronomes latins et leurs conceptions économiques et morales, Paris, Les Belles Lettres, 1971, p. 83 et seq.

${ }^{8}$ Michael von Albrecht, Historia de la literatura romana, Barcelona, Herder, 1994, p. 375 et seq 
Os valerosos romanos

Antes que o tino perdessem,

Donde cuidais que escolhessem

Cincinatos e os Serranos

Que ante sem campo pusessem?

E aquela sua grandeza

Que o tempo não quer que moura,

Vemos que a mais da nobreza

Sobrenomes de riqueza

Não pós, se não da lavoura. ${ }^{9}$

Também era frequente relacionar os argumentos de Catão com as formulações de Hesíodo em Os Trabalhos e os Dias, tão lido e comentado pelos autores de matéria de agricultura da República e do Império romanos, sobretudo no que dizia respeito à lenda das duas Érides. Segundo Hesíodo, a Érides má estimula os homens a viverem em constante dissenso, levando-os à guerra e às disputas fratricidas; ela é a responsável por acender o fogo dos debates cívicos, que terminam quase sempre em inimizade e partidarismos. A Érides boa, nascida das entranhas da terra, pelo contrário, insta todos os seres humanos, em especial, os homens ilustres em virtude, ao arar, ao plantar e ao retirar seu sustento da agricultura, conduzindo-os à riqueza e à felicidade. É assim que Hesíodo adverte, quase numa prece, que se deve gravar no coração a vontade de ver a abundância dos campos para o sustento da casa (o "grão de Deméter") a partir do que a terra produz e, somente depois disso, é possível a dedicação às querelas e aos pleitos sobre negócios alheios nas reuniões públicas, cujo único proveito é trazer preocupações e litígios. ${ }^{10}$

Os "agrônomos antigos", eram, em verdade,
escritores engajados com a tradição dos mais altos
valores romanos, justamente aquilo que fizera de
Roma o grande império do mundo

Para Sá de Miranda, escrevendo exatamente nesse mesmo sentido doutrinal, os ganhos obtidos com o comércio e com as navegações são absolutamente indignos, não só porque trazem muitos efeitos maléficos do ponto de vista moral, mas também porque não condizem com a tradição de hábitos e costumes, que devem ser preservados. É isso, por exemplo, a que se refere quando admoesta Antônio Pereira, seu amigo e vizinho, do prejuízo de trocar a paz e o deleite do campo pela agitação da cidade:

${ }^{9}$ Francisco de Sá de Miranda, Poesias de Francisco de Sá de Miranda, v. 241-250, Lisboa, INCM, 1989, p. 246. ${ }^{10 H e s i ́ o d o, ~ O b r a s ~ y ~ f r a g m e n t o s, ~ v . ~ 28-33, ~ M a d r i d, ~ G r e d o s, ~ 1997, ~ p . ~} 44$. 
Na vila o vilão se abriga

Onde tem nome e herança,

Vive i da sua fadiga.

Acende a fragoa o ferreiro

$\mathrm{O}^{\prime}$ tempo que o galo canta;

Morde o couro o çapateiro,

Brada co o moço ronceiro

Que saia de baixo da manta.

Vive a nobreza por fora

Segura, despovados

Corre cos loubos ousados,

Por d'arredor donde ora

Mantem livre o campo aos gados,

Da mâ gente aventureira

Que ás escuras traz seu trato

Que possa livre quem queira

Cantando ir de noite á feira

Ou dormindo no mulato. ${ }^{11}$

A dedicação à agricultura, para Sá de Miranda, além de cumprir satisfatoriamente a função de obter os recursos materiais que garantiriam a sobrevivência da família, destinava-se a assegurar o ambiente de tranquilidade necessário ao cultivo das virtudes e ao robustecimento do espírito. Nisso, ele concorda perfeitamente com as formulações de Gabriel Alonso de Herrera, um dos principais repositores desse pensamento antigo acerca dos benéficos morais da atividade agrícola, em seu impressionante Agricultura General (1513), cuja fortuna crítica na Península Ibérica ainda não foi devidamente estudada. ${ }^{12}$

O estudo da obra de Herrera, cujo conteúdo a nobreza quinhentista acessava pela leitura coletiva em voz alta nos salões aristocráticos, causava enorme admiração por conta das "reglas de su profesion, de la que no sabian tuviese otras que la practica de sus mayores", sobretudo porque seus conselhos e seu estoque de conhecimentos práticos fundavam-se em muito nos escritos dos antigos romanos, servindo de guia fundamental para aqueles que "siempre se hizieron asi" - o mote tradicional que serve de orientação para toda a sua obra. Manter a tradição - esse "viver à antiga", como tantas vezes insiste Sá de Miranda - era lugar-comum numa sociedade que se estruturava basicamente num "tempo da memória", que deveria ser preservado a qualquer custo. ${ }^{13}$

Os escritores clássicos de re rustica, ou, como se prefere denominar, os “agrônomos antigos", eram, em verdade, escritores engajados com a tradição dos mais altos valores romanos, justamente aquilo que fizera de Roma o grande império do mundo. E, para além das considerações técnicas, é comum encontrarmos referências à decadência moral ou ao esquecimento da sabedoria dos ancestrais (mos maiorum), em que o problema da terra alia-se às mudanças na estrutura social. Nesse sentido, a constatação de que se passava

\footnotetext{
"Francisco de Sá de Miranda, Poesias de Francisco de Sá de Miranda, v. 263-290, Lisboa, INCM, 1989, p. 247. ${ }^{12}$ Gonzalo Anes Álvarez (ed.), La economia española al final del Antiguo Régimen: instituciones, Madrid, Alianza, 1982, p. 64 et seq.

${ }^{13 G a b r i e l ~ A l o n s o ~ d e ~ H e r r e r a, ~ A g r i c u l t u r a ~ g e n e r a l, ~ v o l . ~ I, ~ M a d r i d, ~ I m p r e n t a ~ R e a l, ~ 1818-1819, ~ p . ~} 152$.
} 
por um tempo de decadência, não só da agricultura, mas também de outras artes, configurava um argumento de grande força persuasiva para os que esposavam o pensamento tradicional. Tácito, no Diálogo dos Oradores, referia que a oratória passava por uma profunda crise ("quem ignora que o tempo presente estava muito longe de obter as glórias do passado?", perguntava ele), não por falta de homens destros na arte, porém pela preguiça dos jovens, pela negligência dos pais, pela ignorância dos mestres e, sobretudo, pelo esquecimento ou desprezo pelos valores tradicionais. Esses males, diz Tácito, surgiram em Roma, espalharam-se em seguida pela Itália e agora ameaçam propagar-se pelas províncias. Tácito pensava no debate acerca do melhor orador, descrito no Brutus de Cícero, época em que a vigorosa disciplina dos antepassados fazia surgir varões honrados e ilustres. ${ }^{14}$

Algum tempo antes, Tibulo, autor preferido por Ovídio e por Quintiliano, queixava-se da falta de pax et spes (a tranquilidade do presente e a esperança por um futuro estável) em que vivia a sociedade romana e do clima desfavorável ao cultivo das virtudes. Horácio, que nutria grande admiração por aqueles que se votavam à aristocracia de espírito, fez um longo elogio a Tibulo, apresentando-o como aquele "que se dedicava a tudo que fosse necessário para um homem ser sábio e bom" (Ep. I.4). Admoestando o declínio de Roma, as elegias de Tibulo são exatamente a contraparte das composições que retratam a magnificência das glórias romanas e o clima geral de otimismo presentes no fraseado épico das Odes de Horácio e na Eneida de Virgílio.

Na elegia I.3, Tibulo, advertindo da decadência moral do presente, afirmava a saudade de um tempo passado em que o pastor sonhava em possuir campos imensos para poder alimentar um sem número de ovelhas. Em verdade, essa elegia é um lamento pelo fato de a mulher ter escolhido outro pretendente (mais rico) e ter se mudado para uma propriedade no campo, onde o novo amante pode lhe proporcionar uma vida mais confortável. Tibulo reclama que nessa idade de ferro reinavam a cobiça e a ambição - a corrupção dos costumes, enfim - e não a sinceridade e a simplicidade. ${ }^{15}$

Na elegia I.7, escrita em homenagem a Messala, por ocasião de seu aniversário, mas que remete à sua vitória sobre os povos da Aquitânia, diz que o general, após cumprir a bom termo suas tarefas cívicas, agora poderia render-se ao deus Osíris (o equivalente de Dioniso e de Baco), deus da agricultura (aquele que inventou o arado e ensinou a revolver o solo, a semear os campos e a colher os frutos das árvores) e do vinho para os egípcios. Isto é, que já era tempo de recolher-se para a sua villa no campo e cuidar da administração de sua propriedade rural. A referência estratégica a Osíris, aqui, significa, de um lado, a divindade que criou a viticultura, o retiro reconfortante em época de paz (o vinho cura os males do corpo e do espírito); e, de outro lado, significa a vida no campo, que é a vida sem tristeza, com alegria e graça, sem as preocupações dos negócios da vida civil.

${ }^{14}$ Tácito, Diálogo de los Oradores, Madrid, Gredos, 1988, p. 120.

${ }^{15}$ Tibulle, Tibulle et les auteurs du corpus tibullianum, Paris, Les Belles Lettres, 1955, p. 93-98. 
E, na elegia II.5, dedicada a Valerianus Messala, filho mais velho de Messala, a mais longa de todas as elegias de Tibulo, celebra-se a fundação de Roma; todavia, Tibulo refere que antes de Rômulo ter delimitado a urbs, construindo as intransponíveis muralhas da cidade, não havia diferença entre o campo, as casas e o povo; o monte paladino, o templo de Apolo e a fortaleza do Capitólio seriam, assim, não os índices da magnificência e do esplendor do poderio político, mas a triste contrapartida desse tempo antigo, pacífico e ligado à natureza. É no banquete campesino, realizado na propriedade de Valerianus, num ambiente de paz e em meio a vários produtos agrícolas colhidos no local, que se consegue apaziguar os sofrimentos e a infelicidade. ${ }^{16}$

\section{Essa tradição literária acerca da oeconomia, retirada estrategicamente aos textos clássicos de diversa indole, em muito complementares entre si, é estrategicamente reativada à época do Humanismo}

Com esse mesmo sentido moralizante, os temas da agricultura e seus correlatos também comparecem nas epístolas de Plínio, o Jovem. Na epístola II.17, Plínio elogia sua propriedade rural (a villa de Laurentes), com várias paisagens, vastas planícies, bosques, com muito gado (cavalos, bois, ovelhas) e com clima ameno na primavera; não era grande nem pequena, com poucos gastos na manutenção, com uma casa que serve de abrigo em caso de mau tempo, ampla, bem arejada para suportar o calor do verão, aconchegante no inverno, com abastecimento de água e bom provimento de víveres (retirados do gado e dos pomares), decorada elegantemente, com tudo o que é necessário para uma vida autônoma sem depender dos recursos da cidade. Enfim, digna de um nobre romano. ${ }^{17}$

Na epístola III.19, Plínio solicita ao amigo Rufus, mais experiente na administração de recursos, se deve ou não comprar as terras do vizinho, pois tem dúvidas acerca do preço. O que lhe agrada em particular são as possibilidades de produção agrícola - os campos do vizinho são mais verdes e férteis, a despeito de estarem ultimamente abandonados pelo descuido.

E, mais ou menos por todo o conjunto de suas epístolas, Plínio, como Tibulo, se refere aos problemas tratados pelos preceptistas de agricultura. Trata dos fenômenos naturais, notadamente, na epístola endereçada a Lucinius Sura, em que pede explicações acerca da questão do fluxo e refluxo da água de uma fonte (IV.30); do elogio da propriedade campestre de Rufus (I.3); de uma caçada nas florestas da Toscana em companhia do amigo Tácito (I.6); e sobre os escravos mais aptos ao trabalho rural (I.21).

${ }^{16}$ Ver Tibulle, Tibulle et les auteurs du corpus tibullianum, Paris, Les Belles Lettres, 1955, p. 104-112 e também Michael Putnam, Essays on Latin Lyric, Elegy, and Epic, New Jersey, Princeton, 1982.

${ }^{17}$ Pline, le Jeune, Lettres, tome I, Paris, Les Belles Lettres, 1943, p. 83-90 
Em nenhum lugar pode-se ler de modo tão claro que a agricultura não se restringia simplesmente às técnicas de produção quanto no Sobre o pai de família, de Philo. Ali, ele defende o argumento de que a tarefa primordial do pai de família é conhecer e dominar a si mesmo, sem o que não poderia exercer adequadamente seu papel de mestre da casa. É imediatamente no "prólogo" que Philo declara, pela intervenção do "pai" em sua proclamação inaugural, a razão-de-ser de seu ofício perante a família e sua casa:

as árvores da loucura e da licenciosidade, da injustiça e da covardia, eu cortá-las-ei inteiramente. Eu extirparei as plantas do prazer e dos desejos, da raiva e da ira e de todas as paixões outras descontroladas, mesmo se seus ramos crescerem até o céu. Eu queimarei até as cinzas todas as suas raízes, deixando o fogo consumi-las e hei de persegui-las mesmo se estiveram enterradas nos confins da terra, a fim de não restar traço ou sombra ou parte ou qualquer coisa que seja para trás. ${ }^{18}$

Conquanto seja muito pouco conhecida e estudada atualmente, toda essa tradição literária acerca da oeconomia, retirada estrategicamente aos textos clássicos de diversa índole, em muito complementares entre si, é estrategicamente reativada à época do Humanismo. No século XVI, Piccolomini, em seu famoso tratado acerca da crítica de corte, traduzido para castelhano e publicado em Portugal, depois de responder a seus detratores que lhe imputavam desejar esvaziar os palácios dos reis de fiéis servidores, reativa o exemplo antigo de Giges, considerado o mais ditoso e próspero de seu tempo. Esse rei mítico havia perguntado ao oráculo de Apolo qual era o homem mais feliz na face da terra; como se sabe, a resposta veio imediatamente: era Aglao de Arcádia, porque se esforçava em aperfeiçoar o conhecimento de si por meio do cultivo das virtudes e era, sobretudo, "el qual labraua vnas terrezuelas que tenia: y nu[n]ca su codicia passo de los terminos de aq[ue]lla su heredad"19

A mesma fábula, com o idêntico significado moral, é retomada por Sá de Miranda na carta "A Pero de Carvalho". Depois de realizar uma longa admoestação contra os males da corte, contra os desarranjos da insaciável cobiça e contra as "longas esperanças" ("vãs esperanças", "baldias esperanças") ${ }^{20}$ na obtenção de favores dos grandes senhores, diz Sá de Miranda que:

Gigues na grande abastança

Que de toda a parte ajunta,

Cuidando em tanta possança,

Inchado a Apolo pergunta

Póla bemaventurança.

Tal fumo Apolo entendendo,

Julgou por milhor estrado

O de Aglão que, pastor sendo,

Se vai cantando e tangendo

Olhos somente ó seu gado. ${ }^{21}$

\footnotetext{
18Philo, On husbandry, London, Loeb Classical Library, 1930, p. 128.

${ }^{19 "}$ " o qual cultivava algumas terras que possuía e sua cobiça nunca passou dos limites daquela sua herdade". Enéas Silvio Piccolomini, Miseria de cortesanos... Coimbra, Iuan de Barrera, 1563, fl. 237 (Seção de Obras Raras/ Biblioteca Nacional do Rio de Janeiro, n. 57G,1,18).

${ }^{20}$ Francisco de Sá de Miranda, Poesias de Francisco de Sá de Miranda, vol. 103, Lisboa, INCM, 1989, p. 229; vv. 296; 236.

${ }^{21}$ bidem, vol. 61-70, p. 216-217.
} 
A lição de que a vida na corte inclinava-se ao desarrazoado das paixões e nutria todos os tipos de vícios morais era a pastoral que Sá de Miranda desvelava a um de seus mais diletos amigos, o famoso autor de novelas sentimentais Jorge de Montemayor: "No seas como muchos que sus bienes / Bien no conocen".22 Montemayor se fixara na corte castelhana - muito conhecida à época pela opulência e por onde corriam rios de ouro vindos das possessões no Novo Mundo, que faziam e desfaziam fortunas - provavelmente acompanhando a Infanta D. Catarina por ocasião do casamento com o imperador Carlos V. Ali, conseguira fama de homem erudito, escritor de prestígio e cortesão de rara galanteria, ascendendo em pouco tempo a ofícios de grande importância política. Sá de Miranda admoestava, sobretudo, dos perigos de se devotar a existência à completa irracionalidade dos desejos, de angariar reputação e mercês, ou mesmo de se esforçar para obter fama e renome nas letras.

Na perspectiva adotada por Sá de Miranda, para remediar o movediço dessa desmesura, num mundo marcado pela instabilidade e pela incerteza, o melhor seria reconhecer, desde já, que a verdadeira vida (e não a falsa e inconstante) é aquela fundada, a rigor, na liberdade moral; somente ela resguarda dos reveses da Fortuna e dos golpes das tentações mundanas. Porém, ela só pode prevalecer se baseada nos próprios bens e nunca na expectativa por bens que dependem de outros, quer dizer, em perfeita conformidade com a matriz exemplar dada pela natureza. Assim, é que também Sá de Miranda aconselhava a Pero de Carvalho:

Por mais faminto que venhais,

Morto de sede e de frio,

Fogo onde quer o achais,

Dá vos da sua augua o rio,

E ás vezes de que comais. ${ }^{23}$

Em linhas gerais, esse é igualmente o quadro argumentativo da carta de Sá de Miranda "A seu irmão Mem de Sâ". Aqui, Giges é posto ao lado do mítico Faetonte, cuja petulância em dirigir o carro de Zeus terminaria por calcinar-lhe o corpo, e de Ícaro, que, surdo aos conselhos da prudência paterna, encontrou sepultura entre as ondas, como figuras mais representativas dessa cobiça que infesta o tempo presente. E, na carta "A Antonio Pereira", afirma lapidarmente:

Ah vida de lavradores,

Se eles aconhecessem bem

As avantagens que têm

Aqueles santos suores

Que santamente os mantêm,

Tratando coa madre antiga

Que de quanto em si recebe

(Não entre engano ou mâ liga)

Por seu custume se obriga

A tornar mais do que deve. ${ }^{24}$

22“Não sejas como muitos que seus bens / bem não conhecem”. Francisco de Sá de Miranda, Poesias de Francisco de Sá de Miranda, vol. 139-140, Lisboa, INCM, 1989, p. 459.

23/bidem, vol. 81-85, p. 217.

${ }^{24}$ Ibidem, vol. 191-200, p. 244. 
Os "buenos años" e a "edad dichosa" que Sá de Miranda reconhece como o tempo em que os homens se dedicavam a obter riqueza por meio da agricultura (e, portanto, época em que mais interessava a virtude que o dinheiro) ${ }^{25}$ quadram perfeitamente com a matriz literária contida nas principais obras de Virgílio, autor muito lido e interpretado no século XVI na Península Ibérica, em particular, nas lições (um pouco poéticas) acerca das vantagens e utilidades da agricultura, contidas nas Geórgicas.

Ao final do livro III, Virgílio anuncia a terrível praga que se abate sobre os campos e sobre o gado, contaminando tudo por onde passa. Sem remédio, nem os homens são poupados. A descrição de Virgílio dos cadáveres estendidos e putrefatos ao longo das planícies é particularmente impressionante pela vivacidade. No entanto, ao abrir o livro IV, toda essa fantasmagoria da infelicidade e da destruição esvanece. Um horizonte renovado surge, cuja pureza espalha-se por todos os lados. É o "mel" como presente que escorre das nuvens ("caelestia dona") para a admiração da raça dos homens.

Após isso, tudo está pronto para o novo espetáculo. A dedicatória a Mecenas evoca a vida campestre e a arte da agricultura, que se devem amar e desejar, o que reafirma a projeto de "retorno à terra" da política imperial do governo de Augusto. E, assim, descrevendo as condições favoráveis para a instalação das colmeias e a vida belicosa das abelhas para defender e auxiliar seu rei, e também a vida livre, independente e feliz do jardineiro em sua pequena propriedade rural, Virgílio parece indicar metaforicamente as estratégias mais eficazes para a organização do poder político. ${ }^{26}$ Robert Joudaux ${ }^{27} \mathrm{e}$ Pierre Grimal ${ }^{28}$ já haviam chamado a atenção para esse viés de interpretação. É curioso perceber que a doçura e o charme da vida campestre, em meio ao perfume de diversas flores, e a nobreza, em que vivem os lavradores (a harmonia com a natureza), remetem ao tema do paraíso terreal. As flores dessa "atmosfera arcádica", que o poeta parece adorar, e a imagem recorrente da organização comunitária perfeita das abelhas constroem o ideal de paz política e da estabilidade da ordem social.

A tradição literária também referia que a Idade de Ouro remetia ao passado distante, porém Virgílio, como se sabe, por sua vez, na écloga IV, mudou o sentido das imagens pastoris e as investiu para o futuro como exortação profética. Com o nascimento de uma tão desejada criança, vai cessar a Idade de Ferro, fazendo surgir uma nova raça dourada. Essa nova era da humanidade é o auge de uma progressão histórica, espiritual, ética e política, em que se consegue inverter a sucessão de declínio e corrupção dos tempos. Porém, antes de a prodigalidade do reino de Saturno se instalar, Virgílio vaticina que o mundo passará por uma sucessão de catástrofes e de guerras, em que a ira de um novo Aquiles cairá sobre Tróia. A profecia de Virgílio é clara quanto aos períodos de máximo sofrimento, de corrupção moral e de decadência e de todas as provações, para, enfim, o mundo chegar à Idade de Ouro. Assim, Virgílio, em meio a

\footnotetext{
${ }^{25}$ Francisco de Sá de Miranda, Poesias de Francisco de Sá de Miranda, vol. 174, Lisboa, INCM, 1989, p. 523. ${ }^{26}$ Virgilie, Oeuvres de Virgile. P. Virgilii Maronis opera, vol. I, Paris, Hachette, 1884, p. 56-60.

${ }^{27}$ Robert Joudaux, "La philosophie politique des 'Géogirques', d’après le livre IV (v. 149 à 169)”, Bulletin de la Association Guillaume Budé, n. 1, mars 1971, p. 67-82.

${ }^{28}$ Apud René Martin, Recherches sur les agronomes latins et leurs conceptions économiques et morales, Paris, Les Belles Lettres, 1971, p. 113.
} 
esse "milenarismo", conclama o puer a tomar nas mãos seu destino e provar seu merecimento.

Segundo Helder Macedo, num estudo sobre Camões, a "perspectiva pastoril" e paradisíaca, associada à sucessão das idades do mundo, é contraposta à matéria épica apocalíptica e belicosa. Nesse sentido, as viagens no além-mar, as conquistas de povos antes desconhecidos, as demandas por novas terras e o esforço de conquista só se realizam como sintomática da degeneração e da decadência que caracterizam a Idade de Ferro. ${ }^{29}$ Sá de Miranda, embora não descartasse os feitos militares como uma das formas de se obter honra e fama para si mesmo e para a família, compartilhava com o pensamento antigo que o desejo de sangue, a cobiça material, o saque e a espoliação jamais poderiam mover os que se dedicavam ao cultivo das virtudes. Ovídio, nas Metamorfoses, já havia vaticinado, ao modo de seu contemporâneo Virgílio, que, nos tempos de ferro e da ira sanguinária, as árvores desceriam das altas montanhas e, transformadas em barcos, haveriam de singrar os mares e ultrapassar o perigo das ondas. E que tudo aquilo, que antes estivera em paz e sossego na época áurea do homem (a harmonia e a concórdia perfeitas), estava agora em total desconcerto.

\section{Historicamente, essa literatura de admoestação havia sido cultivada amplamente desde muito cedo nas cortes europeias}

Sobre isso, são conhecidas as intervenções do Velho do Restelo em Os Lusíadas, em que, à partida de Vasco da Gama para as Índias, adverte-se do perigo das proezas realizadas em nome da ambição, do egoísmo, da ânsia de honrarias, das injustiças que se fazem por desculpa da fé, da vontade de glória e fama a qualquer preço, enfim, em nome dos mais odiosos vícios morais. Historicamente, essa literatura de admoestação havia sido cultivada amplamente desde muito cedo nas cortes europeias. E, em meados do século XVI, Sá de Miranda era um de seus principais representantes em Portugal.

O que a voz admoestatória do Velho do Restelo propõe, então, é um "corretivo ideológico" à aventura das navegações, vale dizer, qualquer esforço de se empreender a expansão portuguesa no além-mar deve ser feita por meio do conceito cristão de "guerra justa" e em harmonia com o ideal de paz presente nos valores pastoris da Idade de Ouro e, nunca, na degradação da Idade de Ferro. É esse projeto de paz e império universais, cuja tradição é visível nas práticas políticas do reinado de $\mathrm{D}$. Manuel, que será o aporte principal de Camões e a base para a configuração dos principais sentidos de seu poema. Dedicado ao rei português D. Sebastião, numa época em que o reino e as possessões ultramarinas se viam em constante perigo de derrocada, Os Lusíadas

${ }^{29}$ Helder Macedo, Os Lusíadas: celebração épica como crítica pastoril. Atas da V da Reunião Internacional de Camonistas, São Paulo, USP-FFLCH, 1987, p. 117. 
estabelece que a redenção desse presente decaído política e moralmente se dá necessariamente mediante a recuperação estratégica do heroísmo do passado. ${ }^{30}$

Sá de Miranda, na segurança de seu retiro campesino, concordaria com os versos de Camões acerca do deus Baco, figurando a civilização oriental (indiana), e todas as suas formas de desmesura, como o grande responsável pela atmosfera de desconcerto em que se vivia. Fora ele que, insurgindo-se contra os desígnios da Fortuna e as ordens de Júpiter, suscitou a intervenção dos outros deuses. Todavia, conforme as epístolas de Sá de Miranda, a despeito de se concordar, via de regra, com a "guerra justa" como atividade digna da nobreza de alta estirpe, é preferível a dedicação às letras ("Dias há me escondi, / Co que li, co que escrevi, / Inda me não enfadei”, diz Sá de Miranda a seu amigo Pero de Carvalho) ${ }^{31}$, pois são elas que preparam a cruzada do deus Cupido - não o menino irrequieto que voa, mas o patrono do amor verdadeiro -, o "deus providencial da máquina pastoril" e da restauração da Idade de Ouro, como se refere o estudo de Harry Levin. ${ }^{32}$

Um amor que Jerónimo de Contreras, em sua Selva de aventuras (1542), define numa fábula. O velho pai, em seu leito de morte, determinou deixar toda sua herança para o filho que melhor sustentar sua opinião sobre as mulheres diante de um filósofo:

\begin{abstract}
habéis de saber que en esta ciudad hubo un ciudadano de los más ricos de ella, llamado Cláudio. Este tuvo tres hijos, cuyos nombres son éstos: el mayor, Ardonio; y el segundo, Belio; y el tercero, Basurto. Sucedió que entre estos tres hijos hubo una grande y maravillosa diferencia, así como todos tres fueron de diferentes y extrañas condiciones, porque el mayor, llamado Ardonio, es casado; y el segundo, llamado Belio, jamás se casó, mas fué dado al vicio de las mujeres, no teniendo con ninguna lealtad; el tercero, llamado Basurto, nunca se casó, ni tampoco conoció a mujer, siendo el más enamorado de cuántos en su tiempo ha habido, porque dice que en esto consiste el amor. ${ }^{33}$
\end{abstract}

Dessas três maneiras de amor, o amor pastoril escolherá a terceira, a que melhor expressa a atitude dolorosa e passiva diante do amor, conforme os parâmetros da longa duração histórica da tradição literária, desde os provençais até os poetas palacianos ibéricos, passando pelas versões italianas de Petrarca e seus seguidores da escola poética do Renascimento espanhol, com Garcilaso e Boscán à frente. É nos livros de pastores que essa atitude se agudiza por meio da consciência que supõe essa contemplação convertida em uma profunda introspecção dos movimentos da alma. Sá de Miranda escolheria o primeiro tipo de amor; o casamento e os verdadeiros amigos fazem parte do patrimônio (a "possessión" como parte da "mayordomía", como ressalta Xenofonte) do pai de família, embora concorde que o primeiro momento da economia é conhecer a si mesmo e robustecer o espírito perante os golpes da imponderável sorte.

\footnotetext{
30 José V. de Pina Martins; Eugenio Asensio, Luís de Camões, Paris, Fundação Calouste Gulbenkian, 1982, p. 30. ${ }^{31}$ Francisco de Sá de Miranda, Poesias de Francisco de Sá de Miranda, vol. 288-290, Lisboa, INCM, 1989, p. 224 ${ }^{32}$ Harry Levin, The myth of Golden Age in the Renaissance, Oxford, Oxford University Press, 1972, p. 45. ${ }^{33}$ Apud Francisco López Estrada, Los libros de pastores en la literatura española, Madrid, Gredos, 1974, p. 179-180.
} 